\title{
Teachers' perceptions of autonomy in the tensions between a subject focus and a cross-curricular school profile: A case study of a Finnish upper secondary school
}

\author{
Janne Elo ${ }^{1}\left([) \cdot\right.$ Christina Nygren-Landgärds s, ${ }^{1}$
}

Accepted: 28 November 2020 / Published online: 14 December 2020

(C) The Author(s) 2020

\begin{abstract}
Recent research has indicated global trends of decreasing teacher autonomy and increasing teacher accountability. Standardised national tests have been identified as one of many factors constraining teacher autonomy. Another trend influencing teachers' scope of action is the profiling and branding of schools that compete for students. This qualitative case study concerns the general upper secondary level in Finland, the only level of education in the country with a high-stakes final examination-the matriculation exam. The upper secondary level is generally regarded as Finland's most subject-focused level of education. In contrast to this subject-focused tradition, the case school for this research has developed a cross-curricular profile emphasising creativity, boundary crossing and an outward orientated approach. The study explores the teachers' perceptions of how their autonomy is constrained in this context characterised by tensions between the cross-curricular school profile on one hand, and the subject-focused tradition and student evaluations on the other. Although one might expect these tensions to constrain teacher autonomy, the results show that the teachers, in fact, experience the cross-curricular school profile as increasing their individual autonomy. The study demonstrates that upper secondary teachers can experience extensive autonomy despite global trends of increasing teacher accountability and diminishing teacher autonomy.
\end{abstract}

Keywords Curriculum development · High-stakes testing $\cdot$ School development Teacher autonomy $\cdot$ Upper secondary school

Janne Elo

janne.elo@abo.fi

1 Faculty of Education and Welfare Studies, Åbo Akademi University, Rantakatu 2, 65101 Vaasa, Finland

2 Present Address: Faculty of Humanities and Education, University of Agder, Universitetsveien 25, 4604 Kristiansand, Norway 


\section{Introduction}

Contemporary research has often portrayed teacher autonomy in a very positive manner as, for example, it is positively correlated with job satisfaction, empowerment, engagement and professionalism and is negatively correlated to emotional exhaustion (Erss et al. 2016; Wermke et al. 2019; Skaalvik and Skaalvik 2014; Wilches 2007). However, some research has concluded that autonomy is declining due to recent educational changes, resulting in the deprofessionalisation of teachers (Frostenson 2015). Research on teacher autonomy has focused on investigating the nature of teachers' scope of action and the specific ways in which it is constrained in particular contexts (Frostenson 2015; Mausethagen and Mølstad 2015; Wermke and Höstfält 2014; Wermke and Salokangas 2015). Among many factors, standardised national evaluations generally have negative effects on teacher autonomy (Hopmann 2003; Wermke and Forsberg 2017). Another factor possibly constraining autonomy is the variety of individual school profiles developed to create brands for schools competing for students (Heinrich 2015; Lundström 2015; Lundström and Parding 2011). Developing a school profile is a curricular change process that can be driven either collegially within a school or externally, for instance, by a municipality or a private school owner. Heinrich (2015) suggested that profiling schools might shift the exercise of autonomy from the level of individual teachers to the collegial level. For some teachers, developing a school profile might start a process of unwanted educational changes, limiting their autonomy from the individual perspective.

During the merger of two Finnish upper secondary schools initiated by a municipality, the case school collegially created the profile of the newly merged school and branded it the Creative Upper Secondary School. This distinctly cross-curricular (i.e. non-subject-focused) profile emphasised creativity and an experimental, outward-oriented approach in contrast to the subject- and assessment-focused culture traditionally associated with Finnish general upper secondary schools. General upper secondary schools are the only level of education in Finland that conducts external high-stakes testing: namely, the national matriculation examination (Sahlberg 2007, 2010; Uljens et al. 2016). This national, high-stakes subject-focused test traditionally has made upper secondary schools one of the most subject- and assessment-focused levels of education in the Finnish context. Possible conflicts between the new school profile and these established traditions and practices may create tensions and constrain teacher autonomy, and previous research has suggested that school profiles and national evaluations can both limit individual autonomy (Heinrich 2015; Hopmann 2003; Lundström 2015; Lundström and Parding 2011; Wermke and Forsberg 2017). Research has also pointed out similar tensions between high-stakes subject-focused testing and cross-curricular non-subject goals such as twentifirst-century skills, creativity and innovation (Cachia et al. 2010; Collard and Looney 2014; Erss et al. 2016; Looney 2009; Maustethagen 2013; Nehring and Szczesiul 2015; Sahlberg 2010, 2011). In such situations, teachers might find themselves between two different logics of education: one driven by accountability based on high-stakes testing and a second driven by a collegial vison of socially and morally responsible education (e.g. Sahlberg 2010). 
Our case school provided an opportunity to examine how the teachers' autonomy was perceived to be affected by the tensions between the creative, cross-curricular profile, on one hand, and the subject-focused traditions and practices of Finnish upper secondary schools, on the other hand. The aim of this study was to examine the teachers' perceptions of autonomy in the tensions between the subject-focused tradition and the collegially developed, cross-curricular school profile. This overarching aim was addressed through two research questions: (1) How do teachers think that individual autonomy is framed by the recently developed school profile? (2) How do teachers think that individual autonomy is framed by the national matriculation exam and subject-focused curricula? The study analysis was based on qualitative semi-structured interviews with nine teachers in the case school, with supporting data describing the school profile and merger process. These interviews were conducted after the creative profile was implemented during the first academic year of the new school. This case study produced new knowledge of the teachers' perceptions of autonomy in the tensions between these two different educational approaches and investigated how the collegial process of school profiling could affect the teachers' perceptions of autonomy.

\section{General upper secondary education in Finland}

Post-compulsory education in Finland is divided into vocational education and general upper secondary education, and the latter traditionally is the primary, academicoriented route to university. Finland conducts only one high-stakes national test: the matriculation exam, a subject-specific final test administered since 1874 at the end of students' 3-year general upper secondary school studies (Sahlberg 2007; Uljens et al. 2016). The matriculation exam is based on the national core curricula for general upper secondary education and consists of a minimum of four separate subject tests, with the possibility to take one or more optional tests (Ylioppilastutkintolautakunta, n.d.). Apart from the matriculation exam, all the grading in the individual subject-courses during the 3-year upper secondary period is done by the individual teachers. At the time of this study, the matriculation exam had substantial impacts on university admissions, which were generally based on the combined results of the matriculation exam and university entrance exams (Vuorio-Lehti 2007). Reforms to university admissions implemented in 2018-2020 have aimed at making the results of the matriculation examination the main foundation for university admissions, thus further increasing its status as a high-stakes test (Finnish Ministry of Education and Culture 2017).

As a final test representing the culmination of general upper secondary education, the subject-focused matriculation exam is known to significantly influence teaching, as well as students' expectations and focus (Salmenkivi 2013). Consequently, over the years, Finnish upper secondary schools have been criticised for being too subject focused and for having a culture and tradition centred on preparing students for the exam. According to Antikainen (2006), upper secondary teachers want to safeguard an academic emphasis. Moreover, the idea that the exam serves as a measurement of school quality has been reinforced over the years, for instance, by public rankings of 
schools based on the national exam results (Vuorio-Lehti 2007). According to Müller and Hernández (2010), Finnish teachers have experienced increasing accountability issues, and the matriculation exam has elements of the high-stakes assessment culture sweeping through education systems globally. However, the Finnish education tradition is still believed to emphasise trust and professional autonomy over assessment accountability (Ahonen 2014; Sahlberg 2011; Samuelsson and Lindblad 2015; Uljens et al. 2016).

\section{Teacher autonomy}

Teacher autonomy can be defined as teachers' capacity to independently decide and determine their actions within the given contextual frame of constraints in which they operate (Wermke and Höstfält 2014; Paulsrud and Wermke 2019). Teacher autonomy thus is a multidimensional, complex, context-specific phenomenon existing at different levels (Wilches 2007). The literature features many parallel and overlapping concepts; the same concepts are sometimes used with different meanings, while different concepts are applied to similar phenomena (see e.g. Mausethagen and Mølstad 2015; Ormond 2017; Parker 2015; Prichard and Moore 2016; Vedder and O'Dowd 1999; Wermke and Höstfält 2014; Wilches 2007). Rather than using teacher autonomy as an all-encompassing concept, different levels of autonomy should be discussed separately and in relation to one another to develop a nuanced understanding (Frostenson 2015; Parker 2015; Wermke and Forsberg 2017).

Frostenson (2015) divided autonomy into three levels: the general autonomy of the teaching profession, the collegial autonomy of the individual school and the teacher's individual autonomy of practice. Wermke et al. (2019) presented a similar three-tiered division, labelling the different levels the professional level, the school level and the classroom level. General autonomy refers to the 'organization of the school system, legislation, entry requirements, teacher education, curricula, procedures and ideologies of control' (Frostenson 2015, p. 22). Autonomy at the general level is related to the teaching profession's mandate to influence national-level macro developments that affect teachers' work, such as the requirements for teacher legitimisation and education, privatisation of education and development of national evaluations, curriculum and education policy (Frostenson 2015; Wermke et al. 2018). Extensive general autonomy means that the teaching profession substantially influences the national development of education and the teaching profession, for example, through teachers' unions and teachers' involvement in national curriculum development.

The collegial level of autonomy refers to 'teachers' collective freedom to influence and decide on practice at [the] local level' (Frostenson 2015, p. 23). Collegial autonomy thus focuses on teachers' scope of influence on individual schools' decisions that affect their work (Frostenson 2015; Wermke et al. 2018). These decisions may concern the school curricula, practical organisation of work, schools' common ideologies and visions and development of school brands and profiles. Collegial autonomy focuses on the scope of teachers' joint decision making but should not be confused with school autonomy; the authority of individual schools within 
an education system to decide issues such as budgets, textbooks, hiring and firing (Neeleman 2019). At present, developments in many countries have increased both school autonomy and accountability. Among others, Neeleman (2019, p. 32) has claimed that extensive school autonomy leads to good results only 'in systems with rigorous accountability'. School autonomy can be exercised either in a collegial manner or primarily by the school head and management (Neeleman 2019). Consequently, school autonomy focuses on the degrees of freedom an individual school has as an administrational unit within an educational system, but does not guarantee collective autonomy for teachers and is not synonymous with, or focused on, teacher autonomy. The process of creating a school profile in the present study was not limited to, for example, the headmaster and school board. Instead, the process involved the headmaster and all the teachers, thus exemplifying the exercise of collective autonomy at the school level.

Finally, the individual level of autonomy refers to 'the individual's opportunity to influence the contents, frames and controls of the teaching practice' (Frostenson 2015 , p. 24). Individual autonomy thus encompasses individual teachers' scope of action to decide their teaching work within the prevailing contextual frames (Frostenson 2015; Wermke et al. 2018). At the individual level, a multitude of different factors can contribute to framing the scope of autonomous action. One example of research on individual autonomy is the discussion by Shalem et al. (2018) on the impacts of standardised lesson plans on teacher autonomy.

The levels of autonomy can affect one another, and limited or extensive autonomy at one level may or may not restrict or increase autonomy at another level. According to Frostenson (2015), decisions made at the level of collegial autonomy might restrict the individual autonomy of teachers who are expected to adhere to collegial decisions. However, the collegial level does not necessarily conflict with the individual level if collegial decisions align with individual teachers' perspectives. In this case, the collegial level can be regarded as an expression and an extension of individual autonomy (Frostenson 2015). Kelchtermans (2006) described a similar interpretation that autonomy and collegiality can exist in either a polar relationship, working against each other, or a circular relationship, facilitating and supporting the other. The effects of the exercise of collegial autonomy on teachers' individual autonomy depend, among other factors, on whether the exercise of collegial autonomy is mandated by management or results from teachers' choices (Frostenson 2015).

The interplay between the collegial and individual levels of autonomy is of special interest in this study as the creative profile developed by the case school can be seen as an expression of autonomous decision making at the collegial level. Nonetheless, it is unclear how this exercise of collegial autonomy influences individual teacher autonomy. Collegial autonomy might be a form of decision making delegated by management that may restrict individual autonomy as teachers, regardless of their individual preferences, are expected to adhere to collegial ideals and visions (Frostenson 2015). A school profile can influence teachers' professional roles and place expectations of the educational approaches and methods used, adding to the constraints on teacher autonomy already imposed, for example, by matriculation examinations. However, collegial autonomy also emerges when the 'preferences of 
individual teachers result in collegial action and decisions' (Frostenson 2015, p. 24); therefore, creation and implementation of a profile can increase individual autonomy. Collegial and individual autonomy, especially their interplay, thus are key concepts to studying how autonomy is framed in our case school.

The extent of collegial and individual autonomy in Finnish upper secondary schools in general is an open question. On one hand, Wermke and Höstfält (2014) suggested that the Finnish teaching profession enjoys extensive autonomy at the professional level, but a conservative normative professional culture restricts autonomy at the practice level (the collegial and individual levels according to Frostenson 2015). On the other hand, Erss et al. (2016) showed that Finnish upper secondary teachers appear to experience extensive autonomy at the practice level. The teachers reported not feeling especially constrained, for instance, by the curriculum, materials, methods or teacher accountability (Erss et al. 2016). The restrictions on autonomy they mentioned were primarily related to insufficient resources (Erss et al. 2016). Research thus has raised questions about the nature of teacher autonomy at the practice level in Finland. In our case school, autonomy was possibly restricted by both the high-stakes, subject-focused national assessments and the collegially developed, cross-curricular school profile. Our goal was to examine how the teachers perceived their autonomy in this context.

\section{Method}

This case study dealt with the tensions between the subject-focused traditions and norms and the creative, cross-curricular profile, focusing on the teachers' perceptions of how their autonomy was framed in this context. By chance, we became aware of the school merger and the new school's profile through a newspaper article, and our engagement with the school began after the merger process had been completed. Several types of data typically are gathered for case studies (Cohen et al. 2011), so we obtained information on the case school, the school profile and the creation process of the profile from meetings and e-mail correspondence with the school head, as well as written documents and information from the school's website. A formal interview was also held with the school head. The background data formed the foundation for the following description of the case school and merger process and provided the necessary contextual understanding for interpreting and understanding the teachers' viewpoints in the interviews. Our engagement with the case school began after the merger, so we did not have the opportunity to study, for example, the enactment of teacher autonomy during the merger process.

The aim of this paper was to understand the teachers' views on the constraints on their post-merger autonomy, so the main data source was individual interviews with the teachers. Following an interpretative, hermeneutic approach, semi-structured interviews were conducted to enable the teachers to give voice to their perceptions, opinions and points of view. The advantage of the semi-structured interviews was that they allowed the interviewees to freely elaborate on topics while keeping the discussion on topic (Kvale and Brinkmann 2009; Warren 2002). The interview guide included five core themes, each approaching the question of individual 
autonomy from different perspectives: the school profile, the curriculum, the matriculation exam, collegiality and teacher evaluation. However, the specific questions asked of each teacher varied, providing a significant space to individually shape the interviews to allow the participants to pursue their lines of reasoning.

The entire teaching staff of 33 full time teachers were provided with a letter explaining the study's background and aim and inviting them to volunteer to participate. The nine teachers (six women and three men) who volunteered represented both of the original schools merged into the creative upper secondary school. Seven of the interviewed teachers taught subjects either mandatory or optional in the matriculation exam (mother tongue, second language, biology, geography, religion, psychology, history, civics, math and physics), whereas two taught subjects excluded (music and visual arts). Several teachers taught multiple subjects. The teachers' ages ranged from 33 to 59 years old, and their teaching experience from 5 to 30 years. The school head assisted in coordinating practical arrangements such as scheduling the interviews around the teachers' work days. The on-site, face-to-face interviews were held in school meeting rooms, lasted 31-58 min and were digitally recorded. The interviews were held at the end of the merged school's first academic year, so all the interviewees had experience teaching in the original schools and the new branded school. The interviews yielded a coherent picture, indicating that data saturation had been reached (e.g. Kvale and Brinkmann 2009).

The open coding (Rubin and Rubin 2005) analysis using a hermeneutic approach focused on giving voice to the teachers' perspectives against the background of the specific school context and the general context of the Finnish education system. Both researchers had professional backgrounds as subject teachers, which presumably influenced their interpretations of the contexts and the teachers' perspectives (e.g. Kvale and Brinkmann 2009; Ödman 2007). The data were categorised in numerous rounds according to the research questions until the final categories emerged. Using QSR NVivo 10, the coding was done directly from the audio files to preserve nuances in the interviews generally lost in the process of transcribing (Gibbs 2007). Finally, the analysis results were presented to and discussed with the entire teacher staff at the case school during a seminar in early in fall 2017, approximately 1 year after the interviews were held. Doing so provided a form of validation as the discussion confirmed the results.

\section{The case study's school profile and the merger process}

The purpose of this section is to give readers a sufficient understanding of the study context based on the background material collected for the study. That material consists of information from written documents, the school's website, e-mail correspondence, discussions with the school head and interviews with the school head and teachers.

The case school was in a major city in Finland and had approximately 400 students and 33 full-time teachers at the time of the study. It had recently undergone a major reform as two upper secondary schools merged into a single new school. The two original schools' staff members collaborated in collegial process, beginning 
2 years before the merger, to create the new school's profile. The schools did not make the choice to merge the schools and create a new profile. Instead, the municipality undertook a larger restructuring of the school system and adopted a strategy to profile all upper secondary schools. The schools were given autonomy to lead the profile creation process, and the municipality did not actively influence the process, but the school head kept it informed and regularly reported on the progress.

A team with members from both original schools in our case led the profile creation process. Seminars with the entire staff were held regularly as a collegial forum to advance the process. Various external influences were sought, for example, through dialogue with future researchers, a creativity consultant and education scientists at a local university. Various bodies of literature, for example, on twentyfirstcentury skills also provided inspiration and guidance. The creation of the creative school profile was motivated by the notion that present and future societies would demand competencies other than those traditionally emphasised in upper secondary school. The emphasis on creativity and an open, varied work culture were perceived as establishing alignment with social developments and ensuring the future viability of education. Although driven by the school, the process was simultaneously mandated by the municipality and had elements of branding schools to compete for students.

The process resulted in a vision of 'open-minded education' (School profile matrix). The school slogan of 'The creative upper secondary school—science, humanity and arts' communicated the focus on creativity founded in science, humanity and the creative arts (School head interview). The emphasis on both science and art was intended to convey the desire to break the boundaries between them and to integrate art as a natural element within traditionally more scientific school subjects. The profile gave less focus to the substance of teaching and more to the working and teaching cultures. The mottos of 'breaking the boundaries of the classroom' and 'it's okay to make mistakes' encouraged the teachers and students to actively orient themselves towards society and to dynamically pursue open, experimental approaches to teaching and learning (School profile matrix). The motto 'breaking the boundaries of the classroom' issued an appeal to go beyond traditional classroom teaching, engage in active interactions with the surrounding society, ensure cooperation between the school subjects and teachers and exploit the multiple learning opportunities offered by the school and its environment.

The motto of 'it's okay to make mistakes' positively viewed committing errors as necessary to development and learning. The aim of this motto was to create an open, unthreatening atmosphere for both the students and teachers to challenge themselves and try new things. The school head stressed that this strategy was meant to give the teachers space to actively try different and novel approaches to teaching without the risk of reputational damage or criticisms from colleagues and students in the case of failure. Pursuing new approaches was also linked to evaluation as traditional forms of evaluation did not always align with the school profile or society itself. Traditional student evaluations, to some extent, conflicted with the school profile and the envisioned work culture as evaluations concentrated on demonstrating correct factual knowledge, thus contributing to a culture that focused on subjects and stigmatised mistakes. 
Obviously, this profile was not created in a vacuum as a focus on creativity in education has been a global trend in western societies (Collard and Looney 2014; Shaheen 2010). For instance, the discussion on twentyfirst-century skills has frequently called for more creativity and innovation in education as these are viewed as key skills for technological development, economic competitiveness and solutions to future societal challenges (Collard and Looney 2014; Kalin 2016; Shaheen 2010). Simultaneously, this re-invention of creativity as a decontextualised, fundamental life skill primarily connected to innovation and business has been critiqued as part of a neoliberal discourse on education that has reduced the complexity of creativity to a matter of economic competitiveness, stripping away its critical dimensions (Kalin 2016). In general, creativity has not been especially well defined in educational contexts (Collard and Looney 2014). Against this backdrop, our case school appears to have tapped into the general trend of viewing creativity as a key goal for contemporary education and into the related criticism of traditional education without the often-associated economic emphasis. The key role of arts education in the school profile supported this conclusion.

Neither was the exercise of profiling and branding schools a local phenomenon. The practice of creating school-specific profiles to attract students, arguably influenced by the economic principles of competition and self-preservation, has become a common trend in Western countries (Forsberg 2018; Heinrich 2015). By creating symbolic capital through profiles and brands, schools have tried to position themselves favourably in the competition for students (Forsberg 2018). This practice has become especially prominent in countries with a large proportion of privately run schools and has often been connected to social, ethnical and educational segregation as well as commodification of education (Cucchiara 2008; DiMartino and Butler Jessen 2016; Forsberg 2018). However, this trend of school branding has remained highly uncommon in Finland, with its mostly municipally run schools known for their relatively small differences among them. Nevertheless, the interviews with the teachers and school head showed that to some extent, creating the school profile served to brand the school.

\section{Findings}

This section discusses the results of the analysis of the teacher interviews, presented in two sections with the categories of the results for each research question. Table 1 gives an overview of the result categories.

\section{How does the recently developed school profile frame autonomy?}

The school profile resulted from the exercise of collegial autonomy. The results, therefore, demonstrate how decisions made at the collegial level were perceived as related to the teachers' individual autonomy. 
Table 1 Result categories

How do teachers think that individual autonomy is framed by the recently developed school profile?

The profile increases individual autonomy

The profile comes second to the teachers' own visions

The profile creates a common vision and common expectations

How do teachers think that individual autonomy is framed by the national matriculation exam and subject-focused curricula?

The influence of the curriculum is downplayed

The teachers choose how to relate to the matriculation exam

Tensions exist between the subject-focused examinations and the cross-curricular profile

The matriculation exam is not a measure of accountability

\section{The profile increases individual autonomy}

The study findings show that the teachers utilised their collegial autonomy to create a school profile that mainly increased their perceived individual autonomy. As Frostenson (2015) discussed, this result was not at all self-evident as the exercise of collegial autonomy could have also placed more limitations on individual autonomy. Interviewee number three provided one example of increased perceived individual autonomy:

It's nothing that is being imposed on me. It rather allows me to do something I would like to do anyway.

This statement shows that from this teacher's perspective, the profile was not imposed on the teachers but, instead, legitimated them acting according to their own preferences. The quote indicates that the profile developed at the collegial level of autonomy could be considered to be a 'collegial outcome of individual autonomy' (Frostenson 2015, p. 24), meaning that the teachers used the level of collegial autonomy as an extension of their individual autonomy. This view was also expressed by interviewee number six:

I've done a lot of things that I previously would not have allowed myself to do [...]. I am now allowed to do things that I previously would have had a guilty conscience doing.

This statement shows that the profile not only allowed the teachers to act as they wished but was also perceived as broadening the scope of their possible ways of acting, thereby increasing the scope of their individual autonomy. Interviewee number six mentioned teaching outside of the classroom or school building, giving more responsibility to students, and deciding more freely on teaching contents as examples of the perceived increase in the scope of action. Interviewee number nine provided further evidence supporting this assertion:

This new profile increases flexibility. I don't think it restricts my autonomy; to the contrary, it creates more space for autonomy [...]. 
As these quotes indicate, the teachers appear to have utilised their collegial autonomy in a way that allowed them to increase their perceived individual autonomy in this particular process of change. Creating a profile focused on creativity and breaking boundaries with the assurance that it was all right to make mistakes appears to have broadened the teachers' scope of action from their previous experiences. Their individual teaching preferences gained more latitude as the profile legitimised teaching in the ways they believed to be the most suitable. It, therefore, appears that in this case, the exercise of collegial autonomy was not mandated by management but, rather, extended the teachers' individual preferences and autonomy (see Frostenson 2015).

\section{The profile comes second to the teachers' own visions}

Several teachers also expressed that they experienced extensive individual autonomy as their own professional identities and teaching philosophies influenced their teaching more than the profile did. These teachers thus found support for their individual philosophies in the profile and ultimately subordinated it to their own visions. Interviewee number three expressed such a strong, individual professional identity:

We are all teachers, and we like to "do our own thing". You have to be able to shape your teaching as you see fit as that is when it is at its best [...]. Leading teachers is kind of like herding cats [...].

This statement expresses that a strong individual professional identity was perceived as typical among teachers, who demanded substantial room for autonomous action. Six of the nine interviewees clearly depicted individual philosophies as their main frames of reference. The remaining three did not clearly sub- or superordinate their individual visions in relation to the profile. Interviewee number six gave the following statement:

I myself am the most influential factor in my teaching. I've always been sceptical [of] curricul[a] as I've seen how they work [...]. The profile is the second most important factor as it gives an identity both [to] me as a teacher and [to] us as a school [...].

This teacher clearly stated that their teaching philosophy was foregrounded as the main frame of reference. The profile provided a secondary support for creating the school's common identity. This category demonstrates that the majority of the teachers regarded their own teaching philosophies and visions as their main frames of reference, supported by the profile, indicating that the overall scope of individual autonomy was perceived as extensive, and the teachers did not experience being constrained by the profile to any great extent.

\section{The profile creates a common vision and common expectations}

When contemplating the profile's role in their school at a collective level, the teachers experienced it as a common vision that provided them with a direction and the 
school with an identity. Although the teachers did not explicitly express it, this vision could be interpreted as possibly constraining the teachers' scope of action by placing expectations to live up to the profile on them. Interviewee number three described the profile as a common vision:

It's good to have an image of what we are trying to achieve. It sets a goal, what we want to be. When planning teaching, it's kind of like [the] north star. We aim at being the creative school.

According to this teacher, the profile functioned as a guideline providing the school with a common identity and goal. The profile thus appears to have supported the teachers as they viewed it as a positive influence and a collective vision in line with their individual visions. Interviewee number six, however, indicated that at times, the teachers could experience this common vision as somewhat overwhelming:

I have inner pressure that I could have done this better or differently [...].

This statement shows that the teachers found that the profile increased their scope of action, but at times, it could also create expectations to utilise this scope and live up to the profile's expectations. At the same time, a feeling of not living up to one's own expectations was inherent to the teaching profession, as interviewee number three stated:

I think that most of us at some level think that it could be better, but that's how teaching is; you're never finished.

The teacher stated that a key feature of teaching was its incomplete nature. Consequently, the teachers found themselves in a process of constant development accompanied by the ever-present insight that the practice of teaching did not always correspond to their individual or collective ideals.

Overall, the categories related to the first research question show that the collegially created profile was perceived by the teachers to mainly increase the scope of individual autonomy. However, the profile's influence should not be overrated as the teachers indicated that they also experienced substantial freedom in interpreting the profile and predominantly saw their individual teaching philosophies as the main factors framing their teaching practices. The teachers expressed a strong sense of agency. Together, the result categories for research question one can be interpreted as indicating that the profile created more space for the individual teachers' philosophies and legitimised their exercise of autonomy on the individual level. The final category, though, also indicates that the profile, at least for some teachers, created pressures to live up to the common vision and utilise the existing scope of action.

\section{How do the subject-focused national matriculation exam and the curricula frame autonomy?}

This section presents the teachers' perceptions of how the subject-focused tradition of upper secondary schools, exemplified by the matriculation exam and the curricula, influenced the teachers' individual autonomy. 


\section{The influence of the curriculum is downplayed}

One obvious element that could be expected to frame teacher autonomy was the curriculum. The results, however, show that the teachers had a relaxed approach towards the curriculum. The curriculum's main function was to provide a structure for each subject. Although the curriculum influenced teaching by framing its content, the teachers stated that they did not pay much attention to it, and instead, they tended to base their teaching more on their own professional judgment than the curriculum. Interviewee number two described this situation:

[T] hese curricul[a] that are just paper[s] that no one in day-to-day work reads. Who reads them? [...] I know [that the curriculum is] there. I know what it's about, but it's the least important bit [...].

This statement shows that not only the profile but also the curriculum came second to the teachers' own judgments, as shown in the previous section. Contrary to what might have been expected, the upper secondary teachers did not necessarily see themselves as constrained by the subject-focused curriculum. Interviewee number one states:

If the curriculum says that we should cover [content], well, if we do all of it, it will only be name dropping. I choose what I feel are the most important parts, and so we do less but do it more in depth.

Interviewee number one reported using extensive individual autonomy in relation to the curriculum. The teacher chose to focus on content perceived as important rather than striving to cover all the content. These two statements demonstrate that when deciding on teaching content, the teachers mainly viewed their own professional judgment as more important than the curriculum, revealing a strong sense of agency. The curriculum thus was not experienced to restrict autonomy to a great extent, and its role in framing the teachers' scope of action was downplayed, confirming the findings of Erss et al. (2016).

\section{The teachers choose how to relate to the matriculation exam}

The interviews show that for the subjects evaluated, the national matriculation exam evidently could exert more influence than the curriculum, even to the extent of taking on the role of the main curriculum. The teachers, however, added that the exam was based on the national curriculum, so there was no conflict between the two.

The exam influences [us] a lot. I think it influences [us] more than the curriculum [does].

For interviewee number three, the exam appears to have been the primary influence on decisions regarding teaching content. Interviewee number five expressed a similar view: 
The exam gives me content that I have to address [...]. It's the pupils' legal right [...]. I can't choose that, "Okay, I'm not gonna do this now as this theatre play is on, and we're gonna do something with that instead" [...].

This statement communicates that the need to cover the exam content restricted the flexibility of teaching and the possibilities to utilise teaching methods based on active interaction with the surrounding society, such as project work. The exam is based on the curriculum, but as its scope of subject content tends to be narrower than the curriculum, it appears to be the primary influence on teaching content. The need to cover the content likely to appear in the exam is experienced as restricting individual autonomy. Some teachers also expressed that the matriculation exam influenced student grading in various ways:

The exam is the reference point that you can look at [...]. It functions as a [form of] support when setting the scale.

Interviewee number three perceived the exam as a point of reference for identifying the appropriate levels for grading students in the individual subject courses, which revealed another dimension of the exam's influence. In addition to influencing teaching as a curriculum, it also affected the ways in which students were graded. Interviewee number eight provided a slightly different perspective on the influence on evaluation:

At the end of their studies, I apply the evaluation criteria used in the matriculation exam to show the students that this is what it's about, so they know where they stand.

This teacher perceived that students benefitted when the grading in individual subject-courses used similar types of questions, tasks and evaluation criteria as the matriculation exam. These quotes demonstrate that the matriculation exam, in addition to functioning as a curriculum, could also influence the teachers' student grading. As illustrated by the preceding quotes, the matriculation exam emerged as the culmination of upper secondary school and the main factor constraining the teachers' individual autonomy. These statements confirm that teaching to the test may be a reality in upper secondary schools in Finland.

However, not all the teachers experienced the exam as restraining their scope of action, as exemplified by interviewee number six:

In that regard, I'm perhaps not a "good teacher" as I don't give the exam much attention [...]. My goal is to evoke their curiosity and [to help them] understand how the subject is structured and works [...].

Despite teaching an exam-evaluated subject, this teacher reported that they generally did not allow the exam to influence their teaching, although the teacher was also aware that this approach somewhat violated the norms of upper secondary schools. Interviewee number seven gave another example of the same approach: 
For me, it's never about coaching them to pass the exam. Of course, they have to pass my courses, but it's about orienting outward, taking in influences, working across borders [...].

Although both interviewees six and seven taught subjects included on the exam, they still reported that they did not allow it to influence them heavily. The teachers, in fact, appear to have had autonomy to choose how to relate to the matriculation exam. Some teachers regarded the exam as the main curriculum, whereas others significantly downplayed its influence. Naturally, the teachers of subjects excluded from the exam (e.g. music and visual arts) did not experience it as an influencing factor at all. The results show that the same approach of viewing individual teaching philosophies as the main frame of reference, as witnessed regarding the profile and the curriculum, was also possible with the exam. The teachers appear to ultimately have chosen how to relate to the exam. Consequently, teaching for tests, therefore, could be a reality in Finnish upper secondary schools but did not have to be.

\section{Tensions exist between the subject-focused examinations and the cross-curricular profile}

As the previous categories indicate, the teachers, to some extent, had to balance the subject-focused matriculation exam and the cross-curricular goals of the school profile. As interviewee number three explained, this tension could also be seen as positive:

I think it's rather convenient that they are like two poles that pull in opposite directions. It means that you have to find the balance. You can't go too far in either direction, so it's not a bad conflict, rather a useful tension.

This statement shows that the profile could be perceived as a counterweight to the subject-focused exam, contributing to creating balance. The collegial creation of the profile thus could be interpreted as a means for the teachers to counteract an excessive focus on subjects and to legitimately shift the focus to cross-curricular goals in line with their individual visions. Interviewee number eight supported the view on the tensions as positive:

I think the profile opens the gates to choosing the alternative that is not about sitting in class analysing texts as you would do in the exam [...]. But I'm kind of in between there as everybody writes my subject in the matriculation exam $[\ldots]$.

Although the profile legitimised an increased focus on cross-curricular goals, the teacher stated that doing so should not be achieved at the expense of the subject goals evaluated in the matriculation exam. This teacher, therefore, perceived the tension as simultaneously positive and contrasting with the foundational logic of upper secondary education, making the tension somewhat problematic.

These statements show the teachers' awareness of the need to balance the exam's subject focus and the profile's cross-curricular focus. This tension was mostly experienced as positive by the three teachers who explicitly mentioned 
it, as it was perceived to maintain a balance between the subject and cross-curricular goals. This positive view supported the view that the profile was collegially created as an extension of the teachers' individual teaching philosophies (see Frostenson 2015) to act as a counterforce to the traditional subject focus of upper secondary schools in general and the matriculation exam in particular. Seeing the profile as an extension of individual philosophies meant that tensions existed not only between the subject-focused exam and the profile but also between the individual philosophies and the exam. Using a collegial scope of autonomy to create the school profile, therefore, could be viewed as a way for the teachers to reduce this tension and increase their individual autonomy by supporting their individual standpoints within a collective profile.

\section{The matriculation exam is not a measure of accountability}

The interviews show that the teachers perceived themselves as subjected to only one form of assessment: their individual self-evaluations. The teachers provided no evidence that the matriculation exam results were used to hold them individually accountable. Interviewee number six described a relaxed approach toward this exam:

I'm not personally that concerned with the results [of] the matriculation exam

[...]. I, however, am very self-critical, [...] so I evaluate myself a lot [...].

This teacher did not experience being held accountable for students' exam results. The frame of reference for evaluation, instead, was the teacher's own standards. The pattern of the teachers viewing their own teaching philosophies as superordinate to the profile, curriculum and exam, therefore, was also apparent in the evaluations of the teachers' performance. Interviewee number one also downplayed the importance of the exam as a quality measure and instead emphasised a student-development perspective:

If a student [who] came in with very weak grades develops and gets a 7 or an 8 , then we're very happy. That's a success for us.

As an indicator of teacher success, interviewee number one pointed to the personal development of individual students during upper secondary school rather than their performance on the matriculation exam. The main forms of performance evaluation the teachers reported were the various self-evaluation routines developed by each teacher and the individual development of students, which in practice allowed each teacher to define the characteristics of good teaching. The deprofessionalisation caused by evaluation and accountability across Western countries, therefore, did not appear to have occurred in any great extent in this context, although the matriculation exam could have provided the preconditions for it. Relating to Solbrekke and Englund's (2011) distinction between responsibility and accountability, the teachers in our study clearly communicated that they felt responsible for their students and expressed their obligation to provide the best education possible in the absence of accountability measures. 
The absence of evaluation-based accountability was also evident in the teachers' views on the rankings of upper secondary schools. Although such rankings based on the matriculation exam results was a reality in Finland, the teachers still thought that these rankings did not have substantial effects on their pedagogical decisions, and they did not communicate being held accountable for their schools' rankings.

I think it is more interesting to see how the weaker students have performed. That's where my personal input is more visible. [...] Or to look at the number of students taking the matriculation exam in one of my subjects, that's more important to me [...]. I'd rather see as many students as possible take the exam, struggle and learn than only have the top ones with high grades taking it.

Interviewee number three reasoned that having many students, including academically challenged ones, take the exam (resulting in lower mean grades and school rankings) was more important than having a few students earn top marks. Interviewee number seven supported this view:

Pedagogy is not about rankings. It's about how I can work with these youngsters right here and help them forward. They are here for three years, and then they move on. What can I do with them during these years?

Although upper secondary schools' rankings appear to have had little impact on the teachers' perceptions of autonomy, they were not completely indifferent to the rankings. Interviewee number two illustrated this sentiment:

It's there under the surface, that, "'Ha, ha, this year, we were better than school $\mathrm{xx}$ ".

Although the teachers did not perceive themselves as controlled by or held accountable for the exam results and the consequent school rankings, they did acknowledge this issue, and rivalries between schools appear to have existed.

The results in this category show that the matriculation exam appears to be the main factor perceived to constrain the teachers' individual autonomy. The exam framed the teachers' actions regarding their choice of content and their evaluation of students. For some teachers, the exam appears to have had greater influence than the curriculum, but the extent to which and the ways in which the exam influenced the individual teachers depended on their choices of how to relate to the exam. The exam thus could exert influence but did not necessarily do so. The teachers did not report being subjected to any form of external assessment, or feeling evaluated or held accountable based on students' matriculation exam scores. These results call into question the view on the matriculation exam as a high-stakes exam (Vuorio-Lehti 2007), indicating that the stakes appear to be high primarily for students but not necessarily for teachers. Instead of trying to achieve the best possible mean results for their school, some teachers actively encouraged academically challenged students to attempt non-compulsory tests on the exam, although the teachers had full awareness that doing so could negatively 
affect the school's rankings. These findings support the notion that teacher accountability associated with high-stakes testing is not a dominant element in the Finnish context (Sahlberg 2011), and the negative impacts on teacher autonomy usually associated with high-stakes testing appear to be generally absent.

\section{Conclusions and implications}

In this study, we set out to answer two research questions: 1. How do teachers think that individual autonomy is framed by the recently developed school profile? 2. How do teachers think that individual autonomy is framed by the national matriculation exam and subject-focused curricula? The study found that in the case school, the teachers appear to have utilised their collective scope of action to create a school profile that was an extension of their individual teaching philosophies. This process resulted in a perceived increase in the scope of their individual autonomy after the school merger as their individual philosophies were supported and legitimised. The profile also acted as a counterweight to the otherwise subject-focused tradition and evaluations at the general upper secondary level and legitimised departing from the norms of upper secondary schools. It, therefore, appears that in this case, the level of collegial autonomy was an extension of individual autonomy (Frostenson 2015). The relationship between individual autonomy and collegiality can be described as circular (Kelchtermans 2006) as they facilitated and supported each other.

The findings of high levels of teacher autonomy at both the collegial and the individual level show that in the Finnish education system, extensive autonomy was possible on all three of Frostensson's (2015) levels_-general, collegial and individual. The results can also be interpreted from the perspective of the educational, social, developmental and administrative domains of autonomy (Wermke et al. 2019), showing that this collegial exercise of developmental autonomy placed the developmental and educational domains primarily in the hands of the teachers. The findings also support previous results suggesting a high level of perceived autonomy among Finnish teachers (Erss et al. 2016; Salokangas et al. 2019).

However, the findings also raise questions about the often taken-for-granted picture of Finland as an input-governed education system (e.g. Salokangas et al. 2019). The results show that the matriculation examination played an ambiguous role in constraining autonomy. On one hand, the examination functioned, in many cases, as the main curriculum and as a high-stakes test resulting in the public rankings of schools. On the other hand, the stakes appear to have been high primarily for students, whereas the teachers could choose to allow the exam to influence them to varying degrees. Some teachers gave the exam substantial weight, while others significantly downplayed its influence on teaching, providing a reminder that individual agency and interpretations had significant impacts on how autonomy was experienced and practiced.

The teachers were inclined to regard their own teaching philosophy as their main frames of reference. The profile, curriculum, matriculation exam and school rankings were all secondary influences on the teachers after their own teaching philosophies. This situation can partly be understood against the backdrop of the historical 
development of Finnish basic and upper secondary education through which the teaching profession has acquired substantial autonomy, status and social trust (Simola 2005). The Finnish tradition emphasising trust and autonomy (Sahlberg 2011; Samuelsson and Lindblad 2015; Uljens et al. 2016) has created the preconditions for this open relationship between the teacher and the curriculum or evaluations. In this case, meaning that although some of the teachers thought that the curriculum covered too much subject content, their reliance on their own professional judgment prevented it from hindering their focus on the cross-curricular school profile, exemplifying the exercise of educational autonomy (Wermke et al. 2019). This autonomous approach to the curriculum differs, for example, from Norwegian teachers (Mausethagen and Mølstad 2015) who perceive themselves mainly as deliverers of curricular content and display an unwillingness to take an active role in deciding the content. The results serve as a reminder that success on international student evaluations, such as the Programme for International Student Assessment (PISA), does not have to come at the expense of teacher autonomy, and likewise, it seriously calls into question claims that rigorous accountability is a prerequisite for quality education (Neeleman 2019).

To summarise, this study investigated the outcomes of a merger and development process in which the teachers utilised their collegial autonomy to shape a new school profile that increased their perceived individual autonomy and shifted the focus of education from the upper secondary traditions, making it more in line with their visions of what education should be. In this case, the focus on non-subject goals appears to have been achieved through — not at the expense of - teacher autonomy, providing an example of how the teachers, acting in a collegial manner, could influence the premises and constraints of their work. This was possible, in part, because of Finland's lack of a culture of teacher accountability, even though the matriculation exam provided the means for it, and school rankings have been a reality for many years. The matriculation exam, however, had a major influence on teaching, as it appears to have been the main factor constraining both teaching content and grading.

The findings indicate how context specific and, indeed, individual the interplay of the levels of autonomy is, which future studies need to take into consideration. The results also show that the development of local school profiles can have significant impacts on perceived teacher autonomy. This potential should be taken into account when developing profiles as including teachers in a collegial process of profile development can avoid the otherwise present risk of deprofessionalisation. In this case, the municipality made the decision to develop profiles for all the upper secondary schools, but the creation process was led by the school, making it a topdown and bottom-up process simultaneously. The results suggest that this approach to school development can have positive effects on teacher autonomy rather than the possible negative effects of a purely top-down approach (e.g. Parding 2010).

Naturally, this study has limitations. One possible limitation concerns the selection of the interviewees. Although the interviews produced a coherent picture with data saturation, the selection of different teachers could have produced different results. However, this scenario is unlikely, as the interviews did not indicate clear staff divisions over the profile. The study results were also confirmed when 
presented to and discussed by the teaching staff of the case school during a seminar in early fall 2017, approximately a year after the interviews. A second limitation is that the study is a case study in a specific school at a specific point in time and the validity of the results naturally cannot be generalised beyond these limits. The study shows the possibility of extensive perceived autonomy at all three levels of autonomy in Finland but does not demonstrate that this is the case in every Finnish upper secondary school.

Funding Open access funding provided by Abo Akademi University (ABO).

Open Access This article is licensed under a Creative Commons Attribution 4.0 International License, which permits use, sharing, adaptation, distribution and reproduction in any medium or format, as long as you give appropriate credit to the original author(s) and the source, provide a link to the Creative Commons licence, and indicate if changes were made. The images or other third party material in this article are included in the article's Creative Commons licence, unless indicated otherwise in a credit line to the material. If material is not included in the article's Creative Commons licence and your intended use is not permitted by statutory regulation or exceeds the permitted use, you will need to obtain permission directly from the copyright holder. To view a copy of this licence, visit http://creativecommons.org/licen ses/by/4.0/.

\section{References}

Ahonen, S. (2014). A school for all in Finland. In U. Blossing, G. Imsen, \& L. Moos (Eds.), The Nordic education model. 'A school for all' encounters neo-liberal policy (pp. 77-93). Dordrecht: Springer. https://doi.org/10.1007/978-94-007-7125-3.

Antikainen, A. (2006). In search of the Nordic model in education. Scandinavian Journal of Educational Research, 50, 229-243. https://doi.org/10.1080/00313830600743258.

Cachia, R., Ferrari, A., Ala-Mutka, K., \& Punie, Y. (2010). Creative learning and innovative teaching. Final report on the study on creativity and innovation in education in the EU member states. Luxembourg: Joint Research Centre Institute for Prospective Technological Studies. https://doi. org/10.2791/52913.

Cohen, L., Manion, L., \& Morrison, K. (2011). Research methods in education (7th ed.). Abingdon: Routledge.

Collard, P., \& Looney, J. (2014). Nurturing creativity in education. European Journal of Education, 49, 348-364. https://doi.org/10.1111/ejed.12090.

Cucchiara, M. (2008). Re-branding urban schools: Urban revitalization, social status, and marketing public schools to the upper middle class. Journal of Education Policy, 23, 165-179. https://doi. org/10.1080/02680930701853088.

DiMartino, C., \& Butler Jessen, S. (2016). School brand management: The policies, practices, and perceptions of branding and marketing in New York City's public high schools. Urban Education, 51, 447-475.

Erss, M., Kalmus, V., \& Autio, T. H. (2016). 'Walking a fine line': Teachers' perception of curricular autonomy in Estonia, Finland and Germany. Journal of Curriculum Studies, 48, 589-609. https:// doi.org/10.1080/00220272.2016.1167960.

Finnish Ministry of Culture and Education. (2017). Högskolornas studerandeurval förnyas [Admission to higher education is reformed]. Retrieved November 22, 2018, from https://minedu.fi/sv/artikel/-/ asset_publisher/korkeakoulujen-opiskelijavalinnat-uudistetaan.

Forsberg, H. (2018). School competition and social stratification in the deregulated upper secondary school market in Stockholm. British Journal of Sociology of Education, 39, 891-907. https://doi. org/10.1080/01425692.2018.1426441. 
Frostenson, M. (2015). Three forms of professional autonomy: De-professionalisation of teachers in a new light. Nordic Journal of Studies in Educational Policy, 2, 20-29. https://doi.org/10.3402/nstep .v1.28464.

Gibbs, G. (2007). Analyzing qualitative data. London: Sage.

Heinrich, M. (2015). Metamorphoses of pedagogical autonomy in German school reforms: Continuities, discontinuities and synchronicities illustrated by empirical studies on school development planning, school profiling and school inspection. Nordic Journal of Studies in Educational Policy, 2, 51-61. https://doi.org/10.3402/nstep.v1.28563.

Hopmann, S. T. (2003). On the evaluation of curriculum reforms. Journal of Curriculum Studies, 35, 459-478. https://doi.org/10.1080/00220270305520.

Kalin, N. M. (2016). We're all creatives now: Democratized creativity and education. Journal of the Canadian Association for Curriculum Studies, 13, 32-44.

Kelchtermans, G. (2006). Teacher collaboration and collegiality as workplace conditions. A review, Zeitschrift für Pädagogik, 52, 220-237.

Kvale, S., \& Brinkmann, S. (2009). Den kvalitativa forskningsintervjun [The qualitative research interview]. Lund: Studentlitteratur.

Looney, J. (2009). Assessment and innovation in education. OECD Education Working Papers. https ://doi.org/10.1787/222814543073.

Lundström, U. (2015). Teacher autonomy in the era of new public management. Nordic Journal of Studies in Educational Policy, 2, 73-85. https://doi.org/10.3402/nstep.v1.28144.

Lundström, U., \& Parding, K. (2011). Lärares upplevelser av friskolereformen-effekter av marknadiseringen av den svenska gymnasieskolan [Teachers' experiences of the free school reform-Effects of the marketisation of the Swedish upper secondary school]. Arbetsmarknad \& Arbetsliv[Labour Market \& Working life], 17, 59-77.

Mausethagen, S., \& Mølstad, C. (2015). Shifts in curriculum control: Contesting ideas of teacher autonomy. Nordic Journal of Studies in Educational Policy, 2, 30-41. https://doi.org/10.3402/ nstep.v1.28520.

Maustethagen, S. (2013). Accountable for what and to whom? Changing representations and new legitimation discourses among teachers under increased external control. Journal of Educational Change, 14, 423-444. https://doi.org/10.1007/s10833-013-9212-y.

Müller, J., \& Hernández, F. (2010). On the geography of accountability: Comparative analysis of teachers' experiences across seven European countries. Journal of Educational Change, 11, 307-322. https://doi.org/10.1007/s10833-009-9126-x.

Neeleman, A. (2019). The scope of school autonomy in practice: An empirically based classification of school interventions. Journal of Educational Change, 20, 31-55. https://doi.org/10.1007/ s10833-018-9332-5.

Nehring, J., \& Szczesiul, S. (2015). Redefining high performance in Northern Ireland: Deeper learning and twenty-first century skills meet high stakes accountability. Journal of Educational Change, 16, 327-348. https://doi.org/10.1007/s10833-015-9250-8.

Ödman, P.-J. (2007). Tolkning, förståelse, vetande. Hermeneutik $i$ teori och praktik [Interpreting, understanding, knowing. The theory and practice of hermeneutics]. Stockholm: Nordstedts Akademiska Förlag.

Ormond, B. M. (2017). Curriculum decisions - The challenges of teacher autonomy over knowledge selection for history. Journal of Curriculum Studies, 49, 599-619. https://doi.org/10.1080/00220 272.2016.1149225.

Parding, K. (2010). Lärares arbetsvillkor-handlingsutrymme i tider av förändrad styrning [Teachers' working conditions-Scope of action in times of changing governance]. Didaktisk Tidskrift, 19, 95-111. Retrieved February 27, 2017, from https://www.diva-portal.org/smash/get/diva2:98321 4/FULLTEXT01.pdf.

Parker, G. (2015). Teachers' autonomy. Research in Education, 93, 19-33. https://doi.org/10.7227/ RIE.0008.

Paulsrud, D., \& Wermke, W. (2019). Decision-making in context: Swedish and Finnish teachers' perceptions of autonomy. Scandinavian Journal of Educational Research. https://doi. org/10.1080/00313831.2019.1596975.

Prichard, C., \& Moore, J. E. (2016). Variables influencing teacher autonomy, administrative coordination, and collaboration. Journal of Educational Administration, 54, 58-74. https://doi. org/10.1108/JEA-09-2014-0113. 
Rubin, H., \& Rubin, I. (2005). Qualitative interviewing-The art of hearing data (2nd ed.). Thousand Oaks: Sage.

Sahlberg, P. (2007). Education policies for raising student learning: The Finnish approach. Journal of Education Policy, 22, 147-171. https://doi.org/10.1080/02680930601158919.

Sahlberg, P. (2010). Rethinking accountability in a knowledge society. Journal of Educational Change, 11, 45-61. https://doi.org/10.1007/s10833-008-9098-2.

Sahlberg, P. (2011). The fourth way of Finland. Journal of Educational Change, 12, 173-185. https:// doi.org/10.1007/s10833-011-9157-y.

Salmenkivi, E. (2013). Ylioppilastutkinnon rakenne-ja reaalikoeuudistusten vaikutuksia: Miten lisääntynyt valinnaisuus ohjaa lukiolaisia [The effects of matriculation examination reforms: How increased freedom of choice steers upper secondary students]. Kasvatus \& Aika [Education \& Time], 7, 24-39.

Salokangas, M., Wermke, W., \& Harvey, G. (2019). Teachers' autonomy deconstructed: Irish and Finnish teachers' perceptions of decision-making and control. European Educational Research Journal. https://doi.org/10.1177/1474904119868378.

Samuelsson, K., \& Lindblad, S. (2015). School management, cultures of teaching and student outcomes: Comparing the cases of Finland and Sweden. Teaching and Teacher Education, 49, 168-177. https ://doi.org/10.1016/j.tate.2015.02.014.

Shaheen, R. (2010). Creativity and education. Creative Education, 1, 166-169. https://doi.org/10.4236/ ce. 2010.13026.

Shalem, Y., De Clercq, F., Steinberg, C., \& Koornhof, H. (2018). Teacher autonomy in times of standardised lesson plans: The case of a primary school language and mathematics intervention in South Africa. Journal of Educational Change, 19, 205-222. https://doi.org/10.1007/s10833-018-9318-3.

Simola, H. (2005). The Finnish miracle of PISA: Historical and sociological remarks on teaching and teacher education. Comparative Education, 41, 455-470. https://doi.org/10.1080/030500605003178 10.

Skaalvik, E. M., \& Skaalvik, S. (2014). Teacher self-efficacy and perceived autonomy: Relations with teacher engagement, job satisfaction, and emotional exhaustion. Psychological Reports, 114, 68-77.

Solbrekke, T. D., \& Englund, T. (2011). Bringing professional responsibility back in. Studies in Higher Education, 36, 847-861. https://doi.org/10.1080/03075079.2010.482205.

Uljens, M., Wolff, L.-A., \& Frontini, S. (2016). Finland-NPM resistance or towards European neowelfarism in education? In H. M. Gunter, E. Grimaldi, D. Hall, \& R. Serpieri (Eds.), New public management and the reform of education: European lessons for policy and practice (pp. 39-53). London: Routledge.

Vedder, P., \& O’Dowd, M. (1999). Empowering teachers in times of change. The Swedish comprehensive school system. Scandinavian Journal of Educational Research, 43, 313-326. https://doi. org/10.1080/0031383990430306.

Vuorio-Lehti, M. (2007). Valkolakin hohde. Keskustelua ylioppilastutkinnon merkityksestä Suomessa toisen maailmansodan jälkeen [The glow of the white cap. Discussion on the importance of the matriculation examinations in Finland since World War II]. Kasvatus \& Aika [Education \& Time], $1,19-33$.

Warren, C. (2002). Qualitative interviewing. In J. Gubrium \& J. Holstein (Eds.), Handbook of interview research. Context \& method (pp. 83-102). Thousand Oaks: Sage.

Wermke, W., \& Forsberg, E. (2017). The changing nature of autonomy: Transformations of the late Swedish teaching profession. Scandinavian Journal of Educational Research, 61, 155-168. https:// doi.org/10.1080/00313831.2015.1119727.

Wermke, W., \& Höstfält, G. (2014). Contextualising teacher autonomy in time and space: A model for comparing various forms of governing the teaching profession. Journal of Curriculum Studies, 46, 58-80. https://doi.org/10.1080/00220272.2013.812681.

Wermke, W., Olason Rick, S., \& Salokangas, M. (2019). Decision making and control: Perceived autonomy of teachers in Germany and Sweden. Journal of Curriculum Studies, 51, 306-325. https://doi. org/10.1080/00220272.2018.1482960.

Wermke, W., \& Salokangas, M. (2015). Autonomy in education: Theoretical and empirical approaches to a contested concept. Nordic Journal of Studies in Educational Policy, 2, 1-6. https://doi. org/10.3402/nstep.v1.28841.

Wermke, W., Olason Rick, S., \& Salokangas, M. (2018). Decisionmaking and control: Perceived autonomy of teachers in Germany and Sweden. Journal of Curriculum Studies. https://doi. org/10.1080/00220272.2018.1482960. 
Wilches, J. O. (2007). Teacher autonomy: A critical review of the research and concept beyond applied linguistics. Íkala, revista de lenguaje y cultura [Íkala, Journal of Language and Culture], 12, 245275. Retrieved April 6, 2016, from http://aprendeenlinea.udea.edu.co/revistas/index.php/ikala/artic le/view/2720/2173.

Ylioppilastutkintolautakunta. (n.d.). Matriculation examination. Retrieved August 20, 2020, from https:// www.ylioppilastutkinto.fi/en/matriculation-examination.

Publisher's Note Springer Nature remains neutral with regard to jurisdictional claims in published maps and institutional affiliations. 